\title{
Honeywell
}

\section{Mechanical Devices Readiness FY04.0402.1}

Federal Manufacturing \& Technologies

Thomas R. Bender

KCP-613-8514

Distributed October 2008

Final Report

Approved for public release; distribution is unlimited.

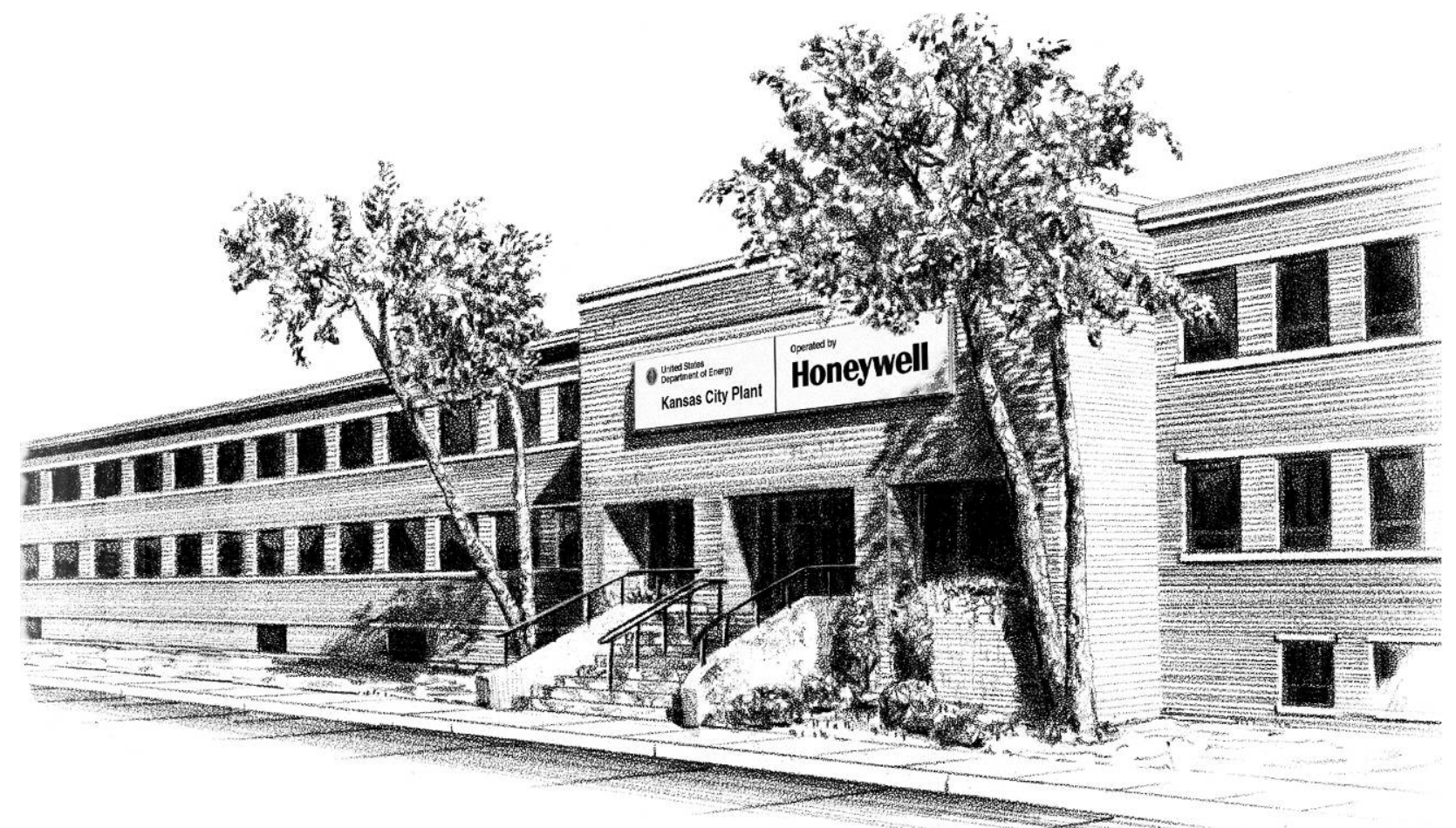

Prepared under prime contract DE-ACO4-01AL66850 for the

United States Department of Energy 


\section{DISCLAIMER}

This report was prepared as an account of work sponsored by an agency of the United States Government. Neither the United States Government nor any agency thereof, nor any of their employees, makes any warranty, express or implied, or assumes any legal liability or responsibility for the accuracy, completeness, or usefulness of any information, apparatus, product, or process disclosed, or represents that its use would not infringe privately owned rights. Reference herein to any specific commercial product, process or service by trade names, trademark, manufacturer, or otherwise, does not necessarily constitute or imply its endorsement, recommendation or favoring by the United States Government or any agency thereof. The views and opinions of authors expressed herein do not necessarily state or reflect those of the United States Government or any agency thereof.

All data prepared, analyzed and presented has been developed in a specific context of work and was prepared for internal evaluation and use pursuant to that work authorized under the reference contract. Reference herein to any specific commercial product, process or service by trade name, trademark, manufacturer, or otherwise, does not necessarily constitute or imply its endorsement, recommendation or favoring by the United States Government, any agency thereof or Honeywell Federal Manufacturing \& Technologies, LLC.

Printed in the United States of America.

This report has been reproduced from the best available copy.

Available to DOE and DOE contractors from the Office of Scientific and Technical Information, P.O. Box 62, Oak Ridge, Tennessee 37831; prices available from (865) 576-8401, FTS 626-8401.

Available to the public from the National Technical Information Service, U.S. Department of Commerce, 5285 Port Royal, Rd., Springfield, Virginia 22161, (703) 487-4650.

A prime contractor with the United States Department of Energy under Contract Number DE-AC04-O1AL66850

\author{
Honeywell Federal Manufacturing \& Technologies \\ P.O. Box 419159 \\ Kansas City, Missouri, 64141-6159
}




\section{Honeywell}

KCP-613-8514

Distribution Category UC-42

Approved for public release; distribution is unlimited.

\section{Mechanical Devices Readiness FY04.0402.1}

Thomas R. Bender

Published October 2008

Final Report

Thomas R. Bender, Project Leader

Project Team:

Tom Bender

Denny Bringman

Jeff Boswell

Tim Castillo

Chad Ellison

John Fanska

Mike Fitzgerald

Aaron Seaholm

Hillary Wheeler

Matt Willoughby 




\section{Acknowledgments}

The author would like to thank the KCP program mechanism engineers, quality engineers, engineering managers, KCP mechanism manufacturing personnel, welding engineers, materials and purchased product engineers, SNL component design engineers, quality engineers, and managers for their innovative contributions, teamwork, and commitment to implement new and improved processes, tooling, and designs. Completion of this project was a team effort. 


\section{Contents}

Section

Page

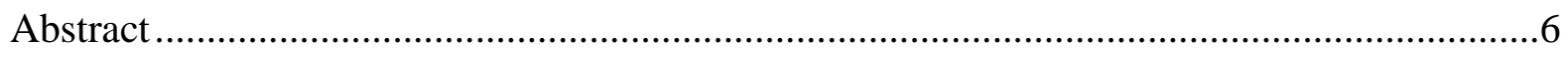

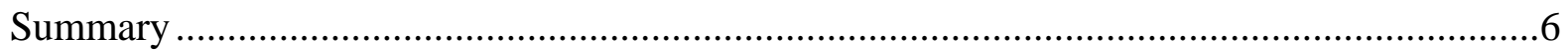

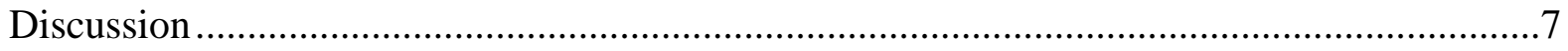

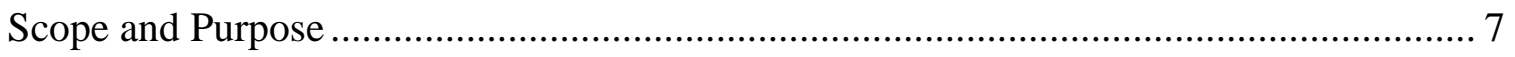

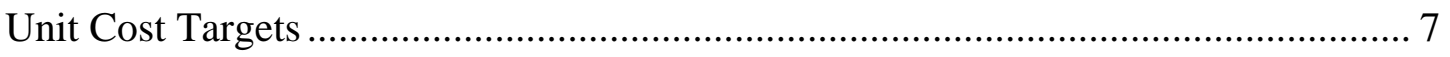

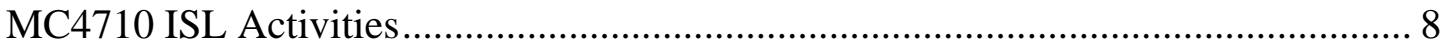

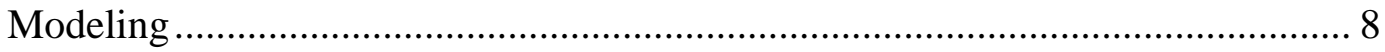

MC4710 Interconnector Protection for Ceramic Headers ................................... 8

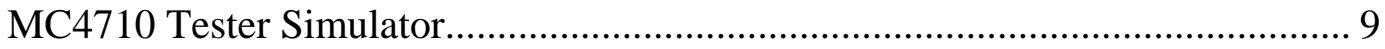

Retrofitted In-Process Tester to Eliminate ISL Bottleneck ................................ 9

Lean Manufacturing Applied on MC4710 ISL and MC4711 TSL....................... 9

Glass Headers to Replace Ceramic Headers in MC4710 ISL............................. 10

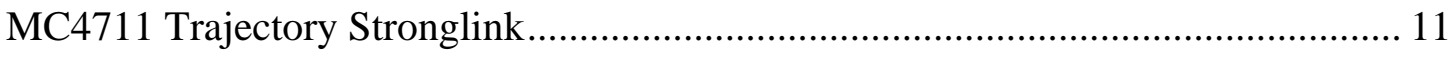

MC4711 Mistake Proofing Activities ............................................................. 11

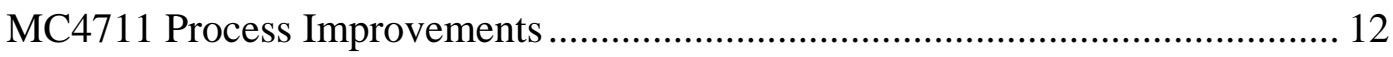

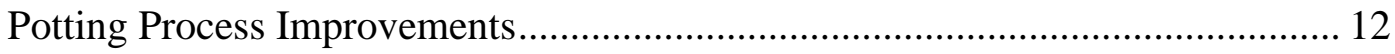

Molydisulfide Lubrication on MC4710, MC4711, MC4653, and MC4654.......... 13

MC4713 Launch Accelerometer..................................................................... 13

Process Development and Characterization...................................................... 13

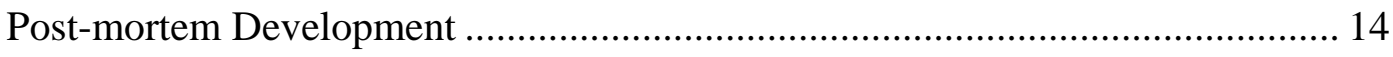


Characterization of Weld Defects (also has separate reports) ................................ 14

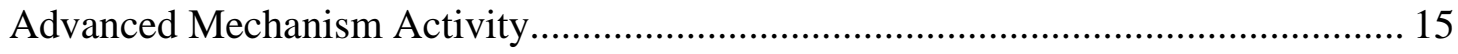

Lubricant Development for Non-Hermetic Mechanisms .................................. 15

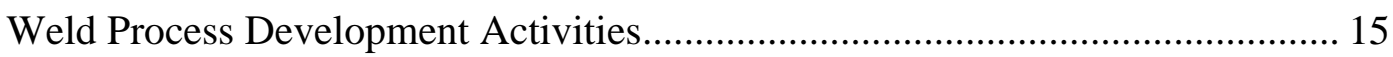

Fiber Laser Weld Machine........................................................................... 16

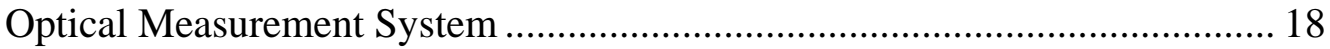

Small Tight Toleranced Parts.................................................................. 18

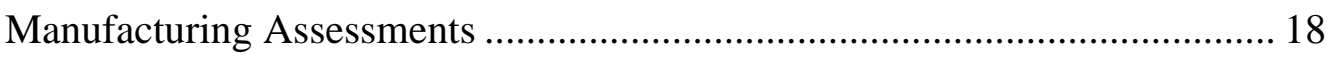

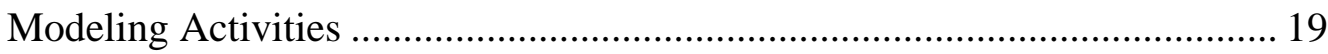

Ceramic Dielectric Strength Evaluation .................................................... 19

Rework Process Development for MC3600A ............................................. 19

Stronglink Activities (706426 MC4654 ISL and 706635 MC4653 TSL) .................. 20

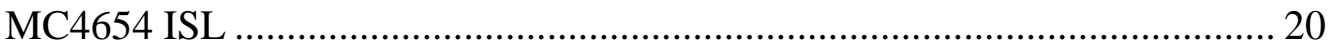

Rotor Assembly Process Improvement................................................... 20

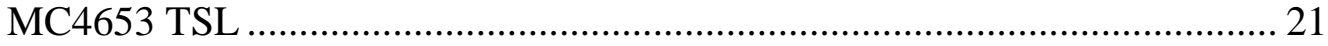

Header Solder Evaluation (Both TSLs) ................................................... 22 
Illustrations

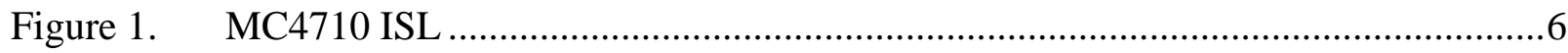

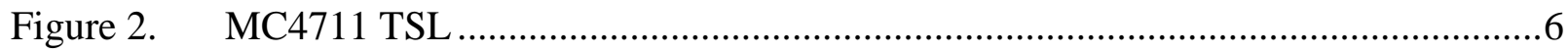

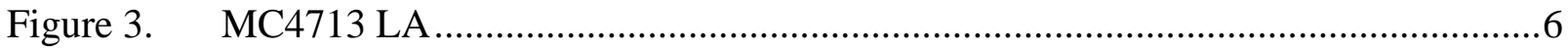

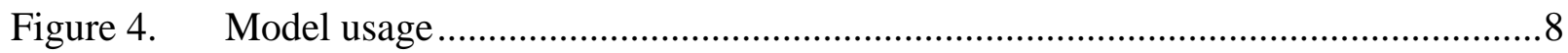

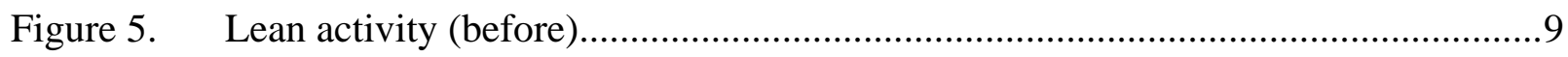

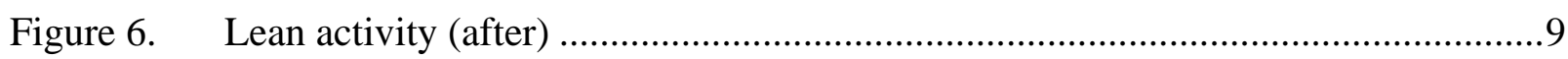

Figure 7. Cross-section of ceramic input header............................................................. 10

Figure 8. Cross-section of glass-to-metal seal input header.............................................10

Figure 9. Photographs of glass-to-metal seal headers ................................................11

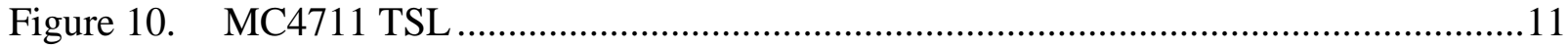

Figure 11. Potted C-cores with excess and cracked potting.............................................12

Figure 12. Potted C-cores with excess and cracked potting...............................................12

Figure 13. Improved potting process with no excess potting or damage.............................12

Figure 14. Improved potting process with no excess potting or damage .............................12

Figure 15. ISL shutter gear; no lubrication (left) and with lubrication (right)......................13

Figure 16. ISL drive arm prior to assembly, all items lubricated.....................................13

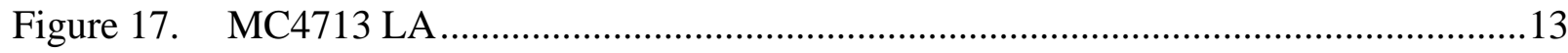

Figure 18. Cross-sections and radiography of spots w/porosity (left) and w/o (right) ..........14

Figure 19. DLN coating on the DSM TSL Pattern Wheel ................................................15

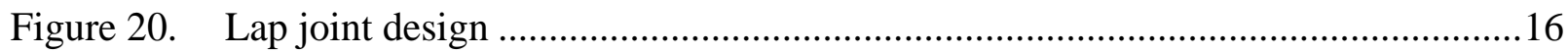

Figure 21. Cross-section of weld penetration using fiber laser welder ..............................17

Figure 22. Weld porosity (gas pockets) from coating contamination .................................17

Figure 23. Prototype optical measurement system.......................................................18

Figure 24. Stereolith model of advanced mechanism ...................................................19

Figure 25. MC3600A instrumented to monitor temperature and vibration .........................20

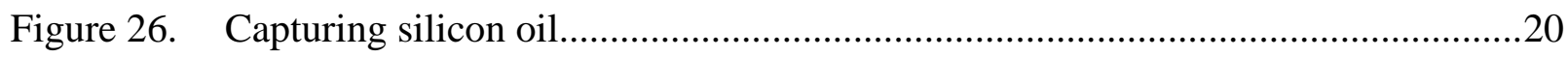

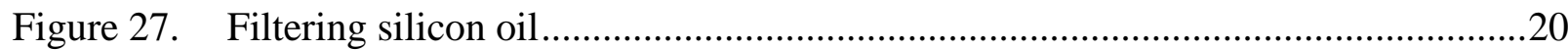

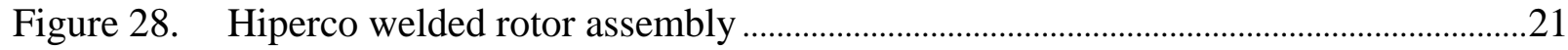

Figure 29. Bolted assembly with mistake proofing pin ..................................................21

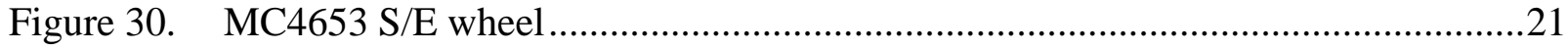

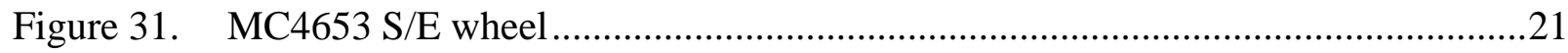

Figure 32. Test pin and sealing glass after tests ......................................................22 


\section{Nomenclature}

$\begin{array}{llll}\text { ADAPT } & \text { Advanced Design and Production } & \text { ISL } & \text { Intent Stronglink } \\ & \text { Technologies } & \text { LA } & \text { Launch Accelerometer } \\ \text { CMM } & \text { Coordinate Measuring Machine } & \text { NNR } & \text { Non-Nuclear Readiness } \\ \text { DA } & \text { Design Agency } & \text { PID } & \text { Production Identification } \\ \text { DLC } & \text { Diamond Like Coating } & \text { PRT } & \text { Product Realization Team } \\ \text { DLN } & \text { Diamond Like Nano-coating } & \text { QE } & \text { Qualification Evaluation } \\ \text { DSM } & \text { Dual Stronglink Mechanism } & \text { SXR'd } & \text { Specification Exception Reported } \\ \text { FPU } & \text { First Production Units } & \text { TSL } & \text { Trajectory Stronglink }\end{array}$




\begin{abstract}
This Advanced Design and Production Technologies (ADAPT) project funded production process and tooling improvements to meet and sustain rate production for the program mechanism assemblies. Techniques were developed to allow evaluation and rework of sealed mechanisms that will result in prevention of the scrapping of future mechanisms. Future system mechanisms will likely be smaller with tighter tolerance parts that will require improved inspection equipment and techniques. During the latter phase of this project, the ISL (Intent Stronglink) PRT (Product Realization Team) developed designs and manufacturing processes at Sandia and at multiple KCP (Kansas City Plant) vendors, to produce glass ceramic headers to replace the brazed ceramic headers in the ISL. This achievement will result in significant production costs savings (unit cost and product scrap due to leaking headers).
\end{abstract}

\title{
Summary
}

The program mechanical assemblies that this project supported are the MC4710 Intent Stronglink, MC4711 Trajectory Stronglink, and MC4713 Launch Accelerometer. Processes and tooling were improved and additional tooling was procured to support First Production Units (FPU) rate production. All FPU schedules were successfully met for these components because of efforts supported by this project. Likewise, rate production schedules are also being supported. This project also supported development of post-mortem processes for the MC4713; developing rework processes for the MC3600A, and evaluating new materials and processes for advanced mechanisms.

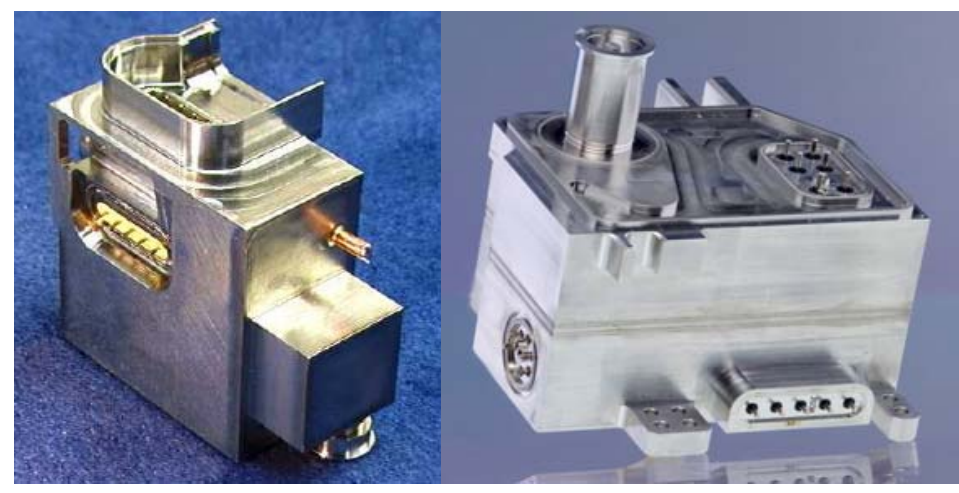

Figure 1. MC4710 ISL
Figure 2. MC4711 TSL

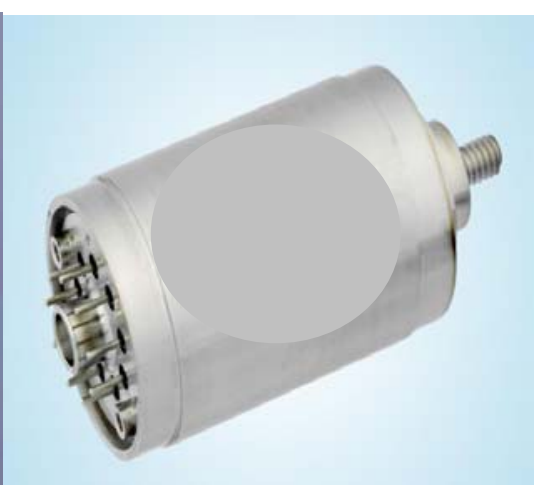

Figure 3. MC4713 LA 


\section{Discussion}

\section{Scope and Purpose}

The scope of this project includes activities on program mechanical devices to support development, characterization and support of production activities to achieve FPU, unit cost targets, and rate production schedules. The scope did not include the day to day support of production, which was funded by Production Engineering, Tooling, and Test Equipment accounts. Concurrent engineering with SNL/NM (Sandia National Laboratories/New Mexico) was used to suggest and incorporate design improvements as well as improve processes and tooling. Goals of these ADAPT projects:

- Develop Stronglink (SL) manufacturing processes to support FPU - completed in October 2006 (MC4710 ISL and MC4711 TSL (Trajectory Stronglink)) and November 2006 (MC4713 LA (Launch Accelerometer))

- Develop SL manufacturing processes to support rate production - completed FY08

o Lean pilot \& yield improvements - completed September 2007

- Achieve/Maintain Cost Targets on SLs - achieved December 2006 and maintained as of August 2008

- Develop welding defect characterization method to reduce or eliminate porosity in laser welds - completed in September 2006 for seam welds and April 2007 for spot welds [SAND Reports for details on welding defect characterization are identified in this report]

\section{$\underline{\text { Unit Cost Targets }}$}

Mechanical Devices ADAPT was successful in improving program processes and tooling to maintain Unit Costs, and developing lower cost headers for the MC4710 ISL. Unit Costs as of August 2008 were:

- MC4710 ISL: $\$ 30900$ which is below the Unit Cost target by $\$ 4700$ (14\% below target)

- MC4711 TSL: $\$ 24200$ which is below the Unit Cost target by $\$ 1200$ ( 5\% below target) 


\section{1: MC4710 ISL Activities}

\section{Modeling}

Utilization of modeling and rapid prototyping helped to create processes and concept tooling, mitigating high risk processes. These models and simulations were incorporated into KCP's Manufacturing Execution System (MES), which is the Production work direction system. This has also aided in training of both the operators and engineers. The teams found errors in ProE models which could have caused vendors to produce defective product and conditions where product would not assemble. The models were beneficial in evaluation of design changes for all 3 mechanisms. Evolution of model usage: (1) Drawings are created in ProE; (2) electronic and stereolith or rapid prototyping models are used to develop initial production routings; (3) models are used by KCP to develop and animate tool designs and improvements; and (4) models are used to create illustrations in production routings.

\section{Drawing/Model Routing Tool model/animation Model for Illustrations}
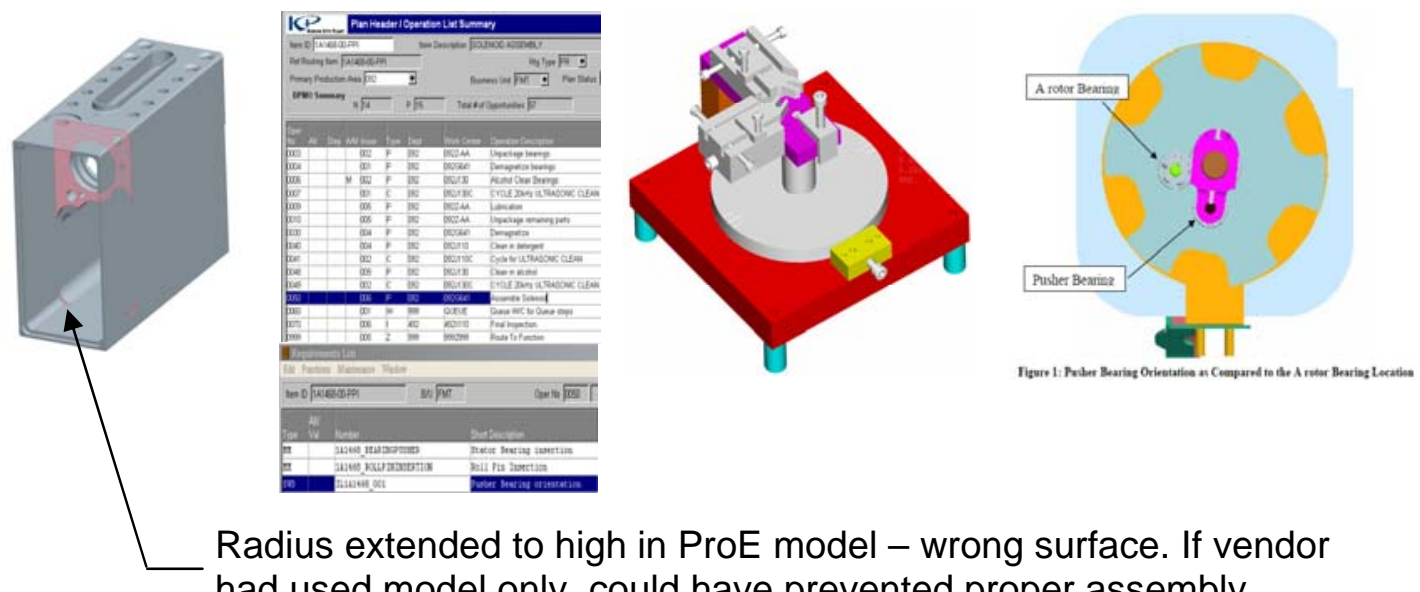

Radius extended to high in ProE model - wrong surface. If vendor had used model only, could have prevented proper assembly.

Figure 4. Model usage

\section{MC4710 Interconnector Protection for Ceramic Headers}

KCP developed interconnectors which were intended to protect ISL headers, preventing damage and product loss at multiple product levels. Stereolith models and molds were created for the interconnector design. KCP ordered 50 sets of these interconnectors from a vendor. While these would conceptually protect the ISL header pins, the mating with the header pins did not provide repeatable connections. 


\section{MC4710 Test Simulator}

Test simulator hardware was procured and assembled. The simulator will allow engineers to determine when baseline tester performance begins to diverge before impact to product testing occurs. The goal of this activity is to minimize test equipment failures and reduce ISL support costs. The simulator will be implemented in FY09.

\section{Retrofitted In-Process Tester to Eliminate Another Program’s ISL Bottleneck}

The in-process testing on the MC4710 would be a bottleneck during the schedule build ahead. To alleviate this problem, a similar program tester was retrofitted to meet another program's requirements. This prevented higher expenditures to build another copy of the test unit.

\section{Lean Manufacturing Applied on MC4710 ISL and MC4711 TSL}

KCP engineers conducted Kaizen events to identify and resolve technical issues that would have resulted in interruption of Qualification Evaluation (QE) Material flow to remain on track to support the FPU milestone. Engineering also initiated lean teams that established processes that are faster and less costly.

The standard hour content was reduced by $6 \%$ as a direct result of lean (elimination of redundant tests and non-valued added tests, and kan-ban activities reduced support materials by up to $65 \%$ in the prime department).

Much of this activity was and continues to be focused on lean organization of the production work areas. Teams created clearly identified storage containers for each tool and/or assembly kit, reducing the time to find tooling and product.

The following figures are photos of the lean organization activity for manufacturing work areas, the tooling storage area, and the tester area.

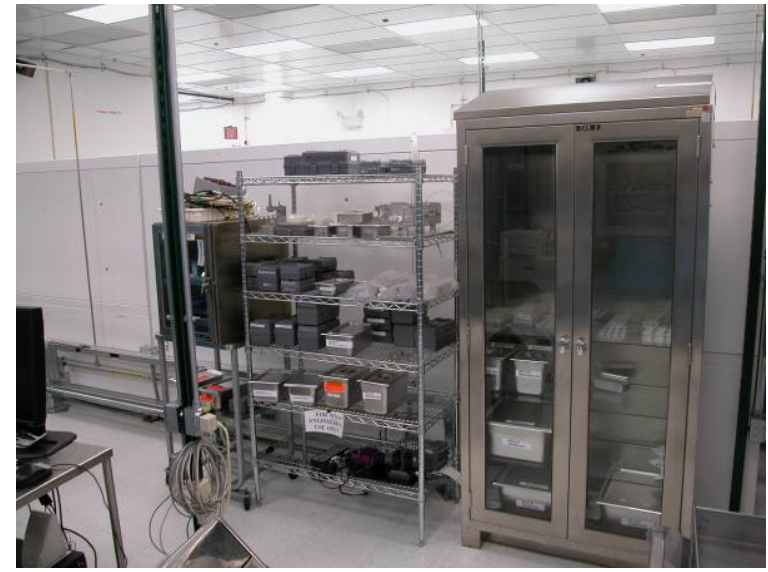

Figure 5. Before lean activities: 30-45 minute prep time to start Production Identification (PID)

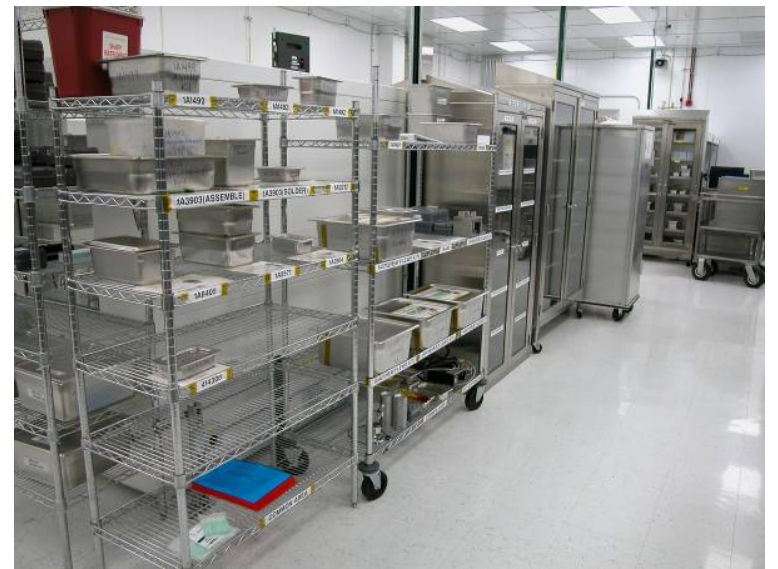

Figure 6. After lean activities: Less than 5 minutes prep time to start PID 


\section{Glass Headers to Replace Ceramic Headers in MC4710 ISL}

These ceramic headers are expensive and leaks developing in the headers have been a problem after they are assembled into the stronglink. Leaks are generally attributed to loads on the ceramic braze joints. A glass-to-metal header design is being developed and evaluated. Savings of approximately $\$ 5000$ per MC4710 and a life-of-program savings of approximately $\$ 12 \mathrm{M}$ are expected.

The team developed two suppliers, in addition to initial development builds from Sandia, to participate in development builds for the glass-ceramic headers. Headers from Sandia were completed and have been installed into MC4710 development units. Assembly and testing of 5 units was completed at KCP. These units will be subjected to existing D-Test processes at KCP.

Headers are in process at both of the KCP suppliers with delivery expected in late FY08. KCP is currently evaluating the hardware with a goal of September 2008 to determine which vendor will be selected for program production.

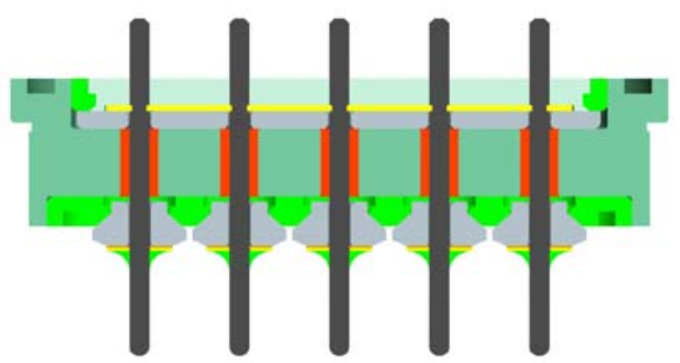

Figure 7. Cross-section of ceramic input header

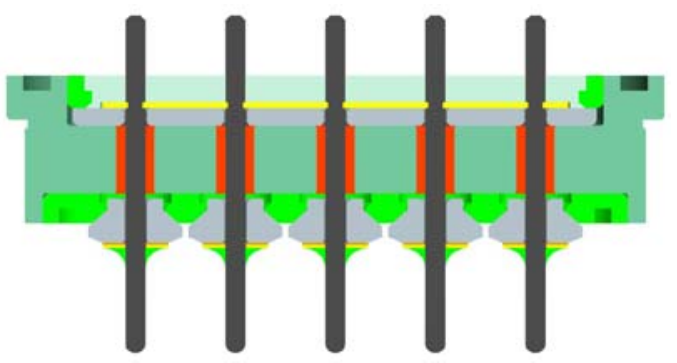

Figure 8. Cross-section of glass-to-metal seal input header 


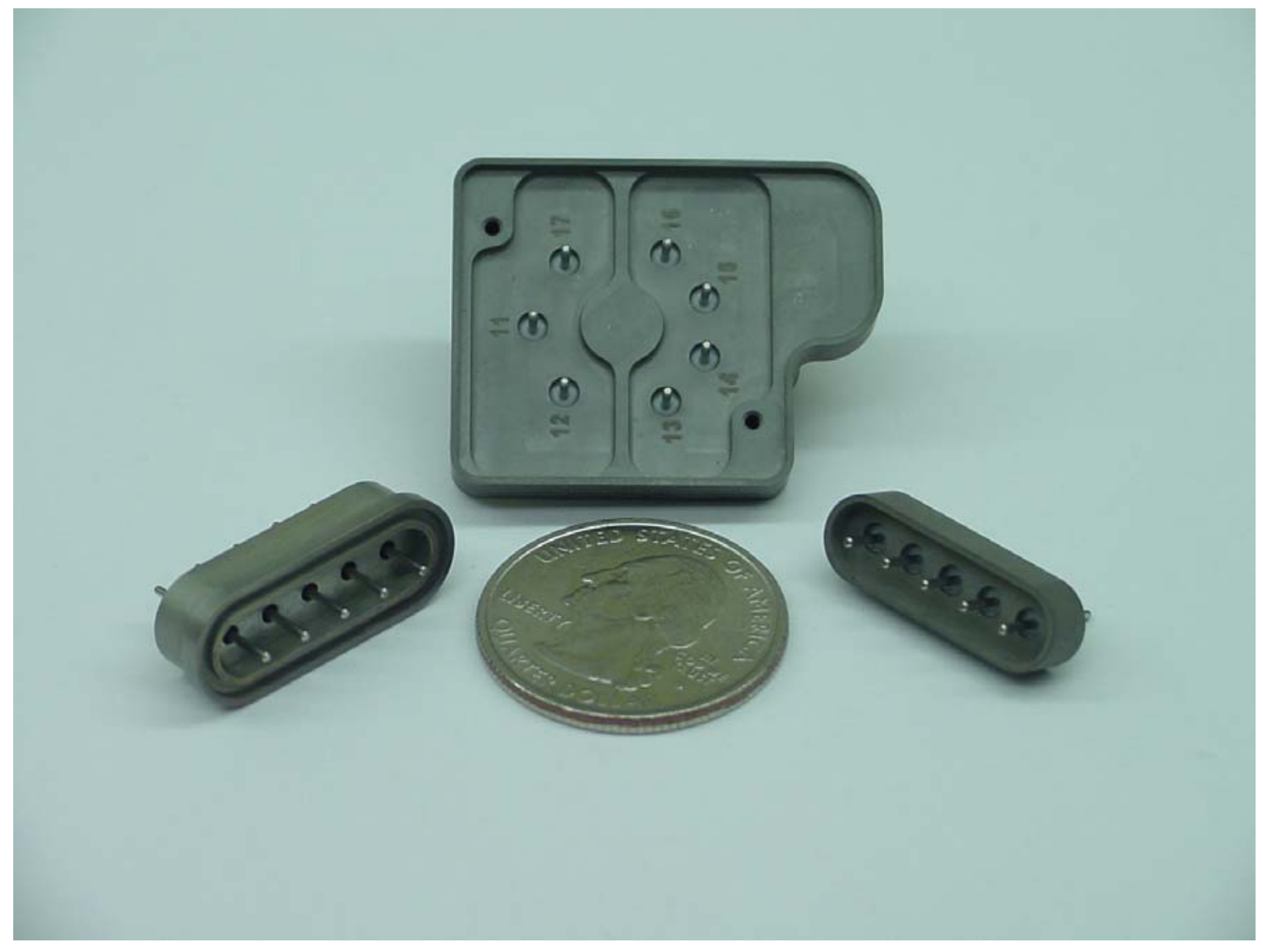

Figure 9. Photographs of glass-to-metal seal headers. Bottom left: Input header assembly (combines header and web which was previously a welded assembly, thus eliminating a weld process). Center: Utility header. Bottom right: Output header

\section{MC4711 Trajectory Stronglink}

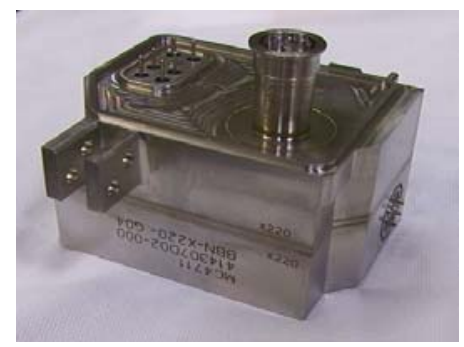

Figure 10. MC4711 TSL

\section{MC4711 Mistake Proofing Activities}

Engineers developed a mistake-proof method for validating test codes consistently, which avoids annual costs of over $\$ 20 \mathrm{~K}$, for TSL and ISL. 


\section{MC4711 Process Improvements}

\section{Potting Process Improvements}

Engineering developed new potting fixtures and a new process for potting the 1A2412 and $1 \mathrm{~A} 2413$ to avoid 50\% of these assemblies being Specification Exception Reported (SXR'd), scrapped, or reworked. These improvements are expected to result in decreased flow-times, standard hours, and material costs.

\section{Before}
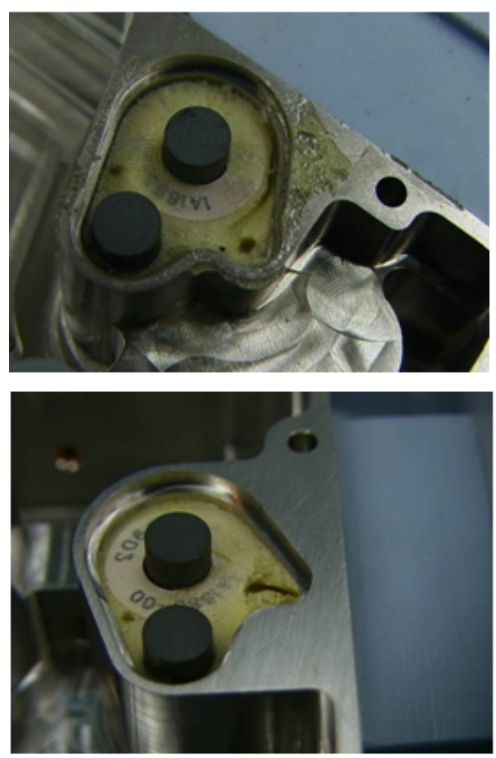

\section{After}
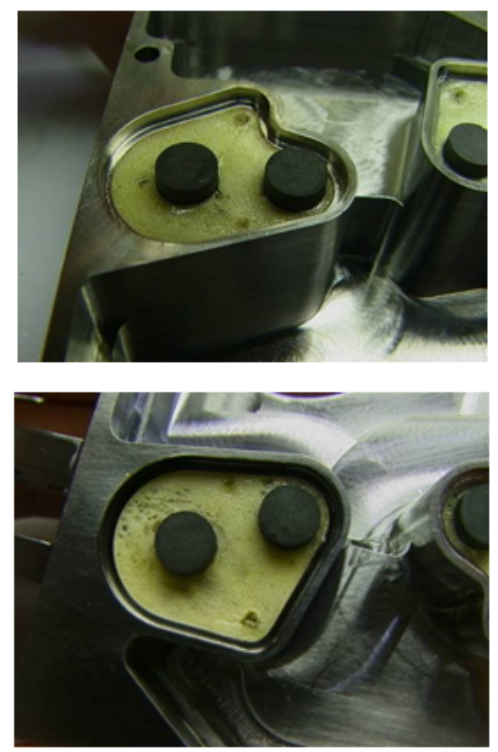

Figures 11 and 12. (left) Potted C-cores with excess and cracked potting

Figures 13 and 14. (right) Improved potting process with no excess potting or damage

Header solder evaluations. See narrative at end of this document in the MC4653 TSL section.

Lubrication processes. The MC4711 requires multiple lubrication processes which are performed at KCP and one bearing vendor. The PRT performed extensive process characterization on all of these processes: Moc2 dry film lubrication application at KCP, MoS2 spray process at KCP, MoS2 harperize process at KCP, and MoS2 sputter at one bearing vendor. These characterizations were performed to control material thickness. Application that is too thin can provide inadequate lubrication, and application that is too thick or peeling leads to binding of parts. The results of this characterization were implemented into the production process at KCP. The multiple processes were required as multiple lubrication processes were required on the stronglink. The significant difference on the MC4711 was the use of the N2 spray process for bearings, rather than the use of Vydax for bearings on the unit. 


\section{Molydisulfide Lubrication on MC4710, MC4711, MC4653, and MC4654}

KCP engineers developed a dry nitrogen spray molydisulfide lubrication process. This activity improves control of process, as the vendor was not consistently processing operations or producing consistent results and KCP had to rely on vendor proprietary process. Developing this process at KCP resulted in significantly reducing lubrication flow time from 10 days to 2 days.
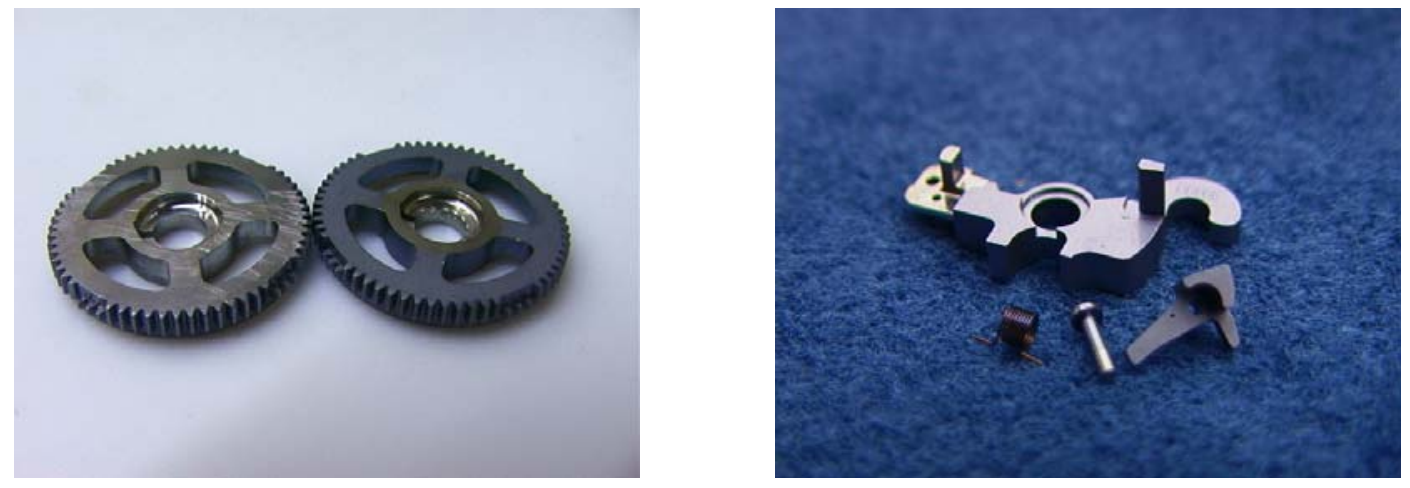

Figure 15. ISL shutter gear; no lubrication (left) and with lubrication (right)

Figure 16. ISL drive arm prior to assembly, all items lubricated

\section{MC4713 Launch Accelerometer}

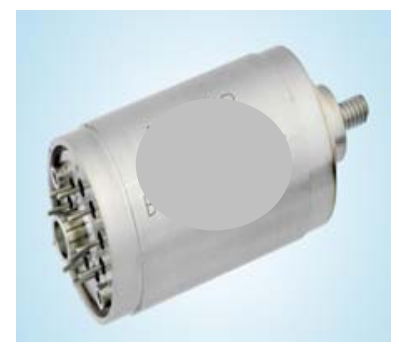

Figure 17. MC4713 LA

\section{Process Development and Characterization}

KCP Engineering provided the funding to perform establish process capability for production of the MC4713. Engineering characterized the PT3698 centrifuge tester, specifically for MC4713 testing. This tester is used on multiple production and surveillance projects. Engineering developed and characterized procurement, fabrication, welding and assembly processes; characterized the contact and insulator adjustment process; and characterized the in-process force-stroke testing, which is a predicator of unit performance prior to welding the unit. KCP Engineering also performed weld characterization and optimization to establish a robust weld for seam welds for the Launch Accelerometer. 


\section{Post-mortem Development}

KCP technicians and engineers developed the processes and draft specification to perform postmortem activities on the MC4713 and subassemblies. The process was utilized in FY08 to perform root cause investigations on several production and D-Test failures.

\section{Characterization of Weld Defects}

Seam and spot weld parameters were analyzed and characterized for porosity. Weld porosity may not be catastrophic; however, in a spot weld where weld strength is commensurate with weld area at the faying surfaces, the loss of weld area due to an undefined or unexpected pore results in undefined or unexpected loss in strength. The goal of the project was to find optimal parameters to achieve minimal porosity at 3 penetrations $(0.010,0.025$, and 0.040 inches). KCP activity was completed in FY07 ahead of schedule. This study has demonstrated that porosity in both long and short-pulse spot welds can be minimized, if not avoided, through informed selection of processing parameters. The final reports are listed below:

\section{SAND2007-1051: EVALUATION OF WELD POROSITY IN LASER BEAM SEAM WELDS: OPTIMIZING CONTINUOUS WAVE \& SQUARE WAVE MODULATED PROCESSES.}

\section{SAND2007-6269: PULSE SHAPING EFFECTS ON WELD POROSITY IN LASER BEAM SPOT WELDS: CONTRAST OF LONG \& SHORT-PULSE WELDS}

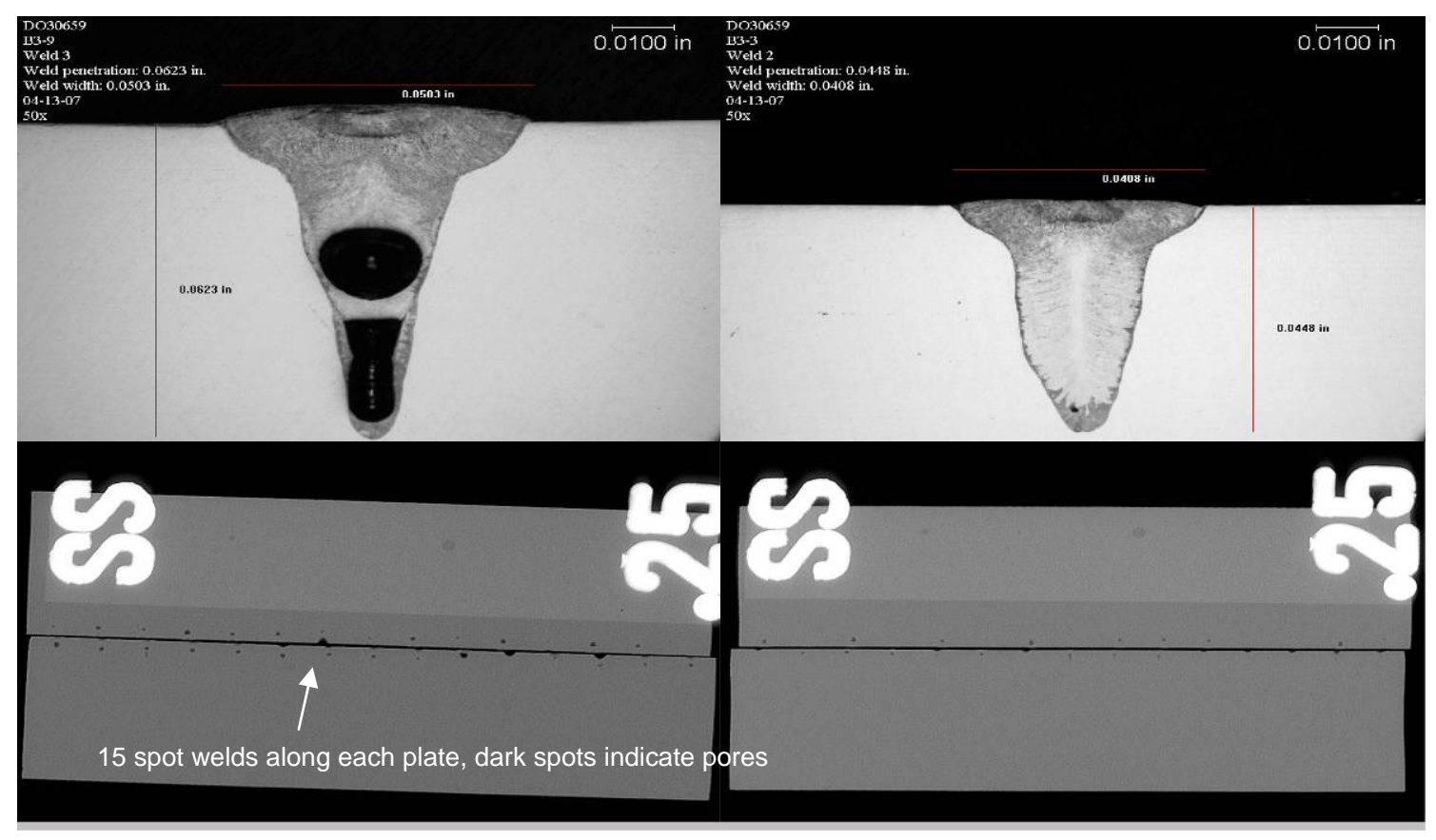

Figure 18. Cross-sections and radiography of spots with porosity (left) and w/o (right). 


\section{Advanced Mechanisms Activity}

\section{Lubricant Development for Non-Hermetic Mechanisms}

Small non-hermetic detonator type stronglinks require different type lubrication than is currently used in conventional hermetic stronglinks. Hard surface diamond-like coatings and diamondlike nanocomposite coatings are being evaluated to serve this purpose. They are used to coat rotational journal pins and rubbing surfaces to prevent galling and increased friction during operation. Sample parts have been sent to two vendors to have these coatings applied. Friction testing performed at KCP and at Sandia/NM looks very promising with the coatings holding up for thousands of cycles with low friction. This project has provided a portion of the funding for these evaluations along with another ADAPT project in another department. Additional impact testing and perfecting of the coatings will be performed in the following fiscal year.

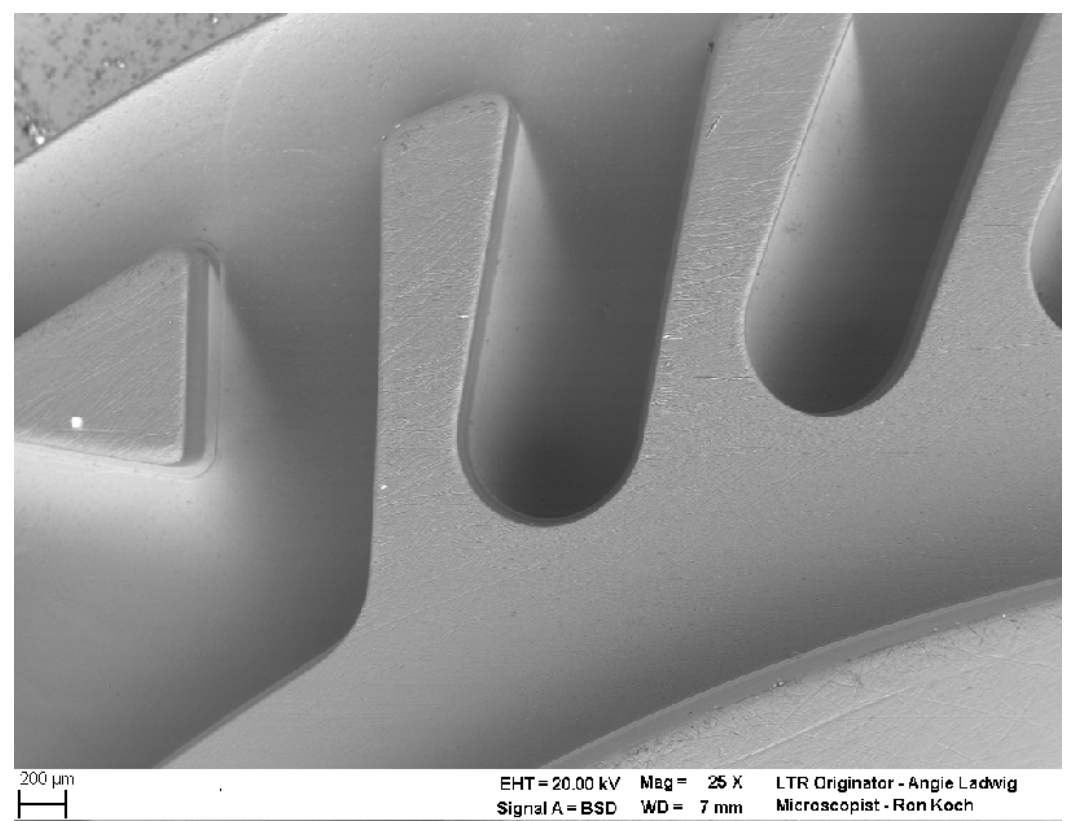

Figure 19. DLN coating on the DSM TSL pattern wheel

\section{Weld Process Development Activities}

Pin Perpendicularity Weld Process Development. The small stronglink model pictured above requires that the welded journal pins be perpendicular to the base plate to less than .0016" to ensure that the rotating parts do not rub on other parts and cause operational failures. Pin weld samples were produced of 21-6-9 and 13-8PH stainless steels and Titanium. The plates with holes to accept the pins were made of 21-6-9. The design fit-up between the pin and hole is from a .0002” interference to a .0004” slip fit. This is the design used in current Sandia stronglink designs. Weld schedules were developed using various power settings, focal length lenses, etc. All sample welds resulted in weld perpendicularity readings of less than .0012". See the DSM Welding Activities report in the appendix. 
Preferred and Lap Joint Weld Development. KCP is recommending the use of a preferred weld joint in many cases because control of the weld penetration can be more accurately held. This is because the weld joint is controlled by the thickness of one of the machined pieces. Only a full penetration through this piece is needed which eliminates the difficult to control max / min penetrations of the typical butt joints currently used. Another joint that would also be an improvement in some cases would be a lap joint. Preliminary weld schedule development at KCP has been completed.

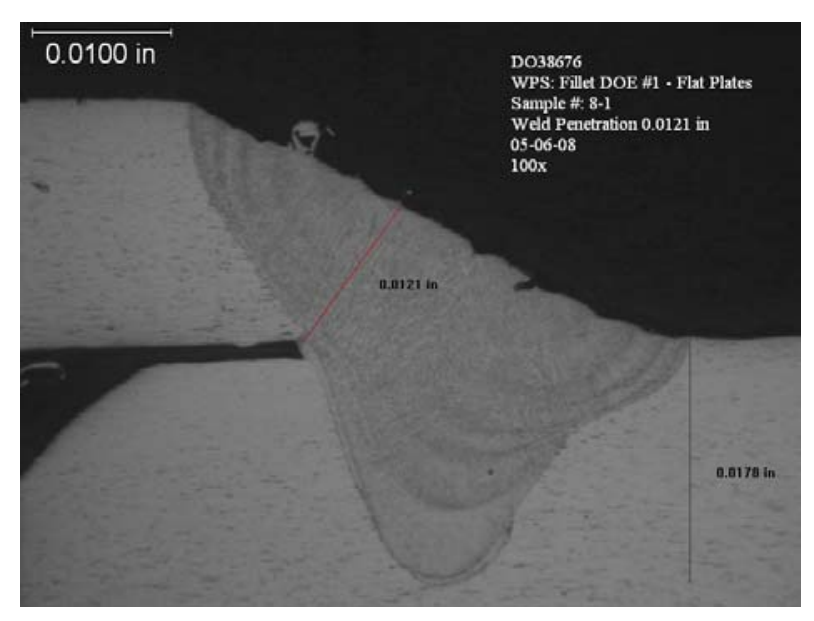

Figure 20: Lap joint design

Evaluation of Chrome Core 13XP Welds. The preferred magnetic steel for mechanism solenoids has been Hiperco 50 or 50A. However, even though this material is the most efficient magnetic material, it has some problems. It rusts very easily, is brittle, and does not weld well. A material that is nearly as magnetically efficient and that does not rust is Chrome Core $13 \mathrm{XP}$. It is also not a desirable material to weld, but should weld better than Hiperco. Samples were produced and welding evaluations have begun. Preliminary results show that the weld joints are superior to Hiperco, but further evaluation will continue.

\section{Fiber Laser Weld Machine}

Investigations were made into a different type of welding machine that can produce smaller tack welds with deeper penetration. The photo below shows a weld taken at Ohio State University using a fiber optic laser machine. A KCP weld engineer visited Ohio State with samples to evaluate their fiber weld machine. The laser light is directed to the joint to be welded by an optical fiber instead of through air when focused by a lens. The weld shown is approximately .004 " in diameter and has a .031" penetration. As mechanism designs become smaller, smaller welds may be needed. 


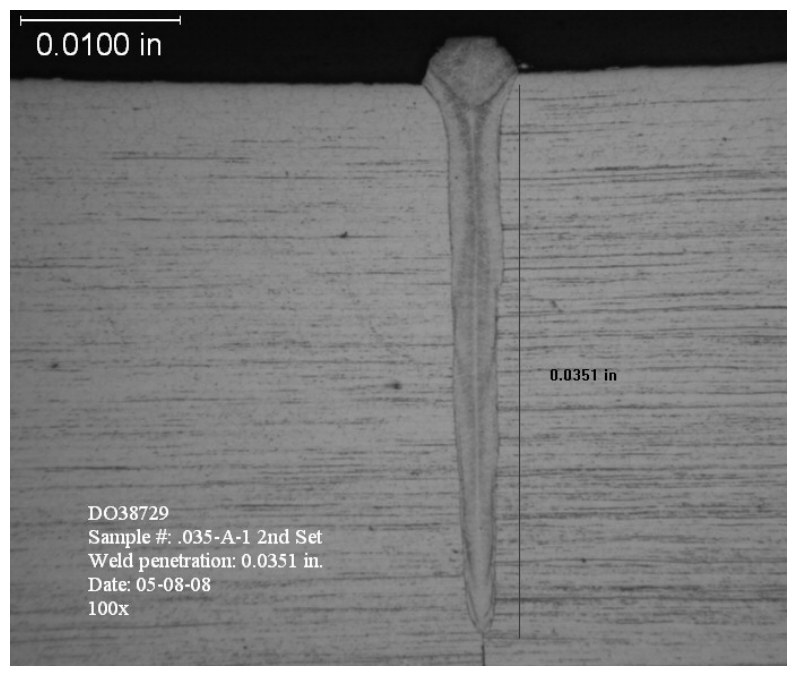

Figure 21. Cross-section of deep and narrow weld penetration using fiber laser welder

Welding of DLC or DLN Coated Parts. Foreign material on parts to be laser welded is known to be undesirable. However, at times it is difficult to completely mask areas to be coated with hard coatings like DLC (Diamond Like Coating) and DLN (Diamond Like Nano-coating). These coating are very thin, in the order of a micron or two. Evaluations were performed to determine if coatings could be allowed on a part in the weld joint area. Samples were coated and welded. The photo below shows that it is not acceptable to have any of the coating in the joint area. The joint was hollow in the center because of the carbon in the coating vaporizing during the welding process. Adequate masking techniques will have to be developed prior to production applications.

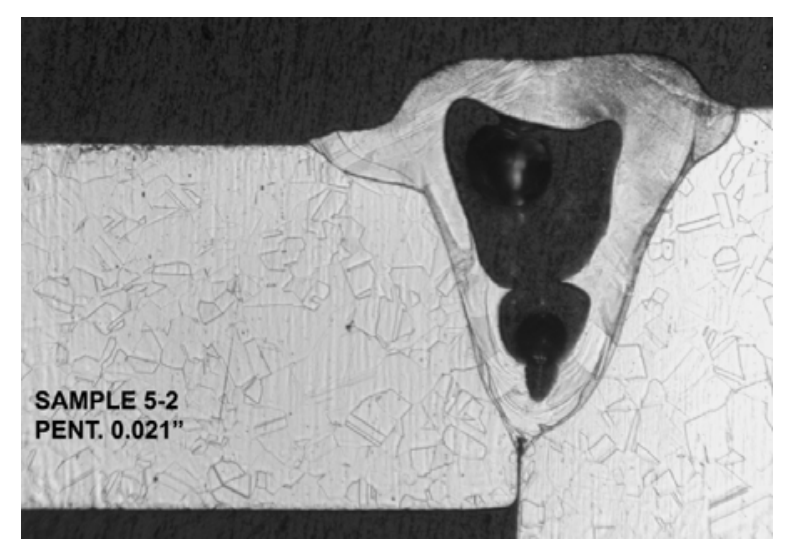

Figure 22. Weld porosity (gas pockets) from coating contamination 


\section{Optical Measurement System}

A special design optical measurement system was designed and built to improve inspection capabilities of optical comparators and vision systems for small mechanism parts. This project validated the Virtual Optical Comparator concept. Another project funded the validation that this optical system could clearly view and measure features on the surface of the Dual Stronglink Mechanism (DSM) TSL pattern wheel. The commercial system also offers software for programming the part contours from the drawing ProE file and offers a much easier to interpret graphical output of the inspection data. The final prove-in and calibration will be continued in FY09 using the Mechanical Devices Readiness project.

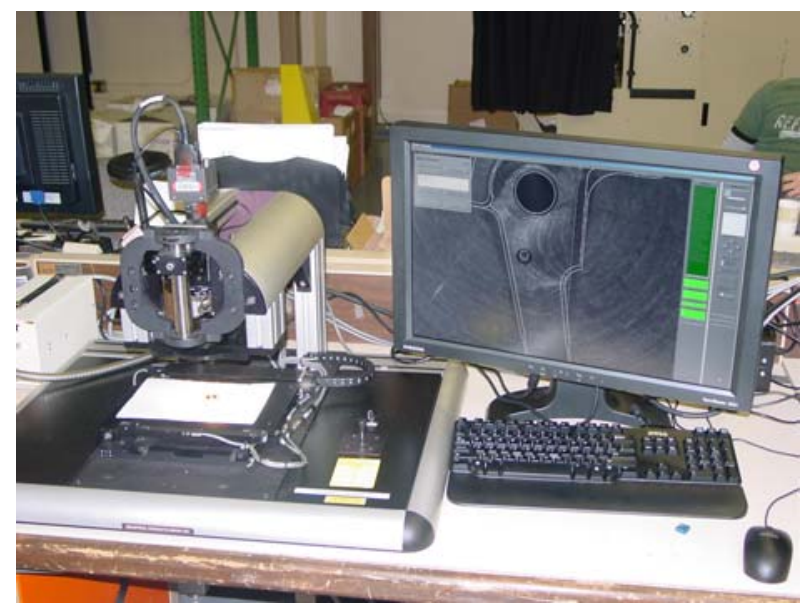

Figure 23. Prototype optical measurement system

\section{Small Tight Toleranced Parts}

A new concept $30 \mathrm{~mm}$ Dual Stronglink design has a factor of 10 fewer parts than conventional stronglinks because it uses complex .010" thick flat parts that incorporate many part functions into one part. The part has contour tolerances as small as .0008”. To determine if parts can be procured that meet these tolerances, the drive arm was procured from an outside vendor. A vendor machined the parts with state of the art micro wire EDM (Electro Discharge Machining). This part incorporates the pattern wheel, drive rotor, springs (beam springs), and lock pawls all in one part. The parts were inspected using the Werth optical Coordinate Measuring Machine (CMM) at KCP and then with the new optical measurement system described above.

\section{Manufacturing Assessment}

A manufacturing assessment of the more difficult Detonator Stronglink Mechanism (DSM) parts was done with two vendors. SNL and KCP engineers met with the vendors, resulting in numerous drawings improvements. This activity early in the development phase will result in drawings that are much more manufacturable. This will result in considerable future 
cost savings, according to the vendors, because of lower machining times, inspection times, tooling costs, scrap, and ability to machine some parts on less costly equipment.

\section{Modeling Activities}

KCP created stereolith models of the program stronglink design to evaluate assembly processes. These models were used to make manufacturability suggestions before ordering expensive real parts, and to develop improvement suggestions on spring mounting, optical monitor designs, and wiring improvements for very small solenoid wires were given to and are being incorporated by the Design Agency (DA). Previous mechanism designs were also modeled and manufacturability improvement suggestions were given to the DA, leading to a redesign.

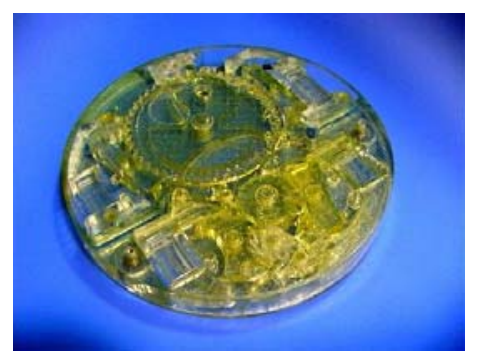

Figure 24. Stereolith model of advanced mechanism

\section{Ceramic Dielectric Strength Evaluation}

Current dielectric strength requirements for the program Launch Accelerometer and Intent Stronglink ceramic parts are causing problems in accepting the ceramic material. The specification on the drawings calls out to test the material with $1 / 4$ " thick samples, with the option to test at other thicknesses. However, when tested with $1 / 4$ ” thick samples, failures occur. When tested with 1/8" thick samples, the material passes. However, the actual part thickness used are thinner than 1/8”. Data is being collected at actual part thicknesses so that an improved product test requirement can be developed.

\section{Rework Process Development for MC3600A}

A potential to save approximately $\$ 2.5 \mathrm{M}$ has led to developing a rework process for the MC3600A Launch Accelerometer. Eighty units have been on hold because of the potential that the spring cup could have a burr that was witnessed on some units. If the sealed units can be machined open, checked for burrs, cleaned, reassembled, refilled with oil, welded shut again, and retested, they may be able to be sold. This could save $\$ 2.5 \mathrm{M}$. Several portions of the overall rework process have been developed. For example, the external ceramic insulators were difficult to remove without leaving metal marks, and the RTV was difficult to remove. Cutting the RTV sufficiently to remove the screws would leave metal marks. Instead, it was found that the screws could be loosened without leaving metal marks, then the ceramic could be baked at $650 \mathrm{C}$ with the screws still in place. The RTV would turn to powder, allowing the screws to fall out and allowing the RTV residue to be cleaned easily. 


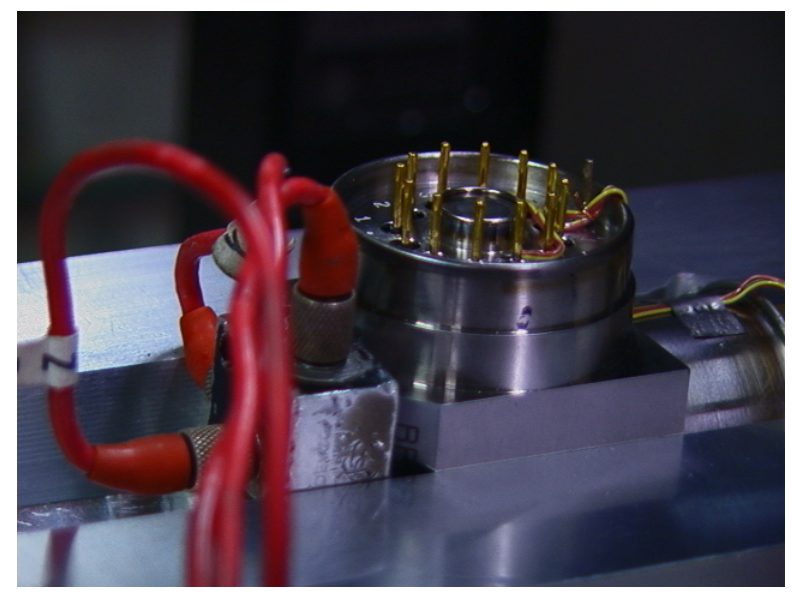

Figure 25: MC3600A instrumented to monitor temperature and vibration during machining

KCP is currently developing cleaning processes to clean the various piece parts and subassemblies once disassembled. A big portion of this effort is capturing cleaning solution on filters as the parts are being cleaned, so that the filters can be analyzed to determine the level of cleanliness. The goal is to ensure that the disassembled components are as clean as the components that go into new units.

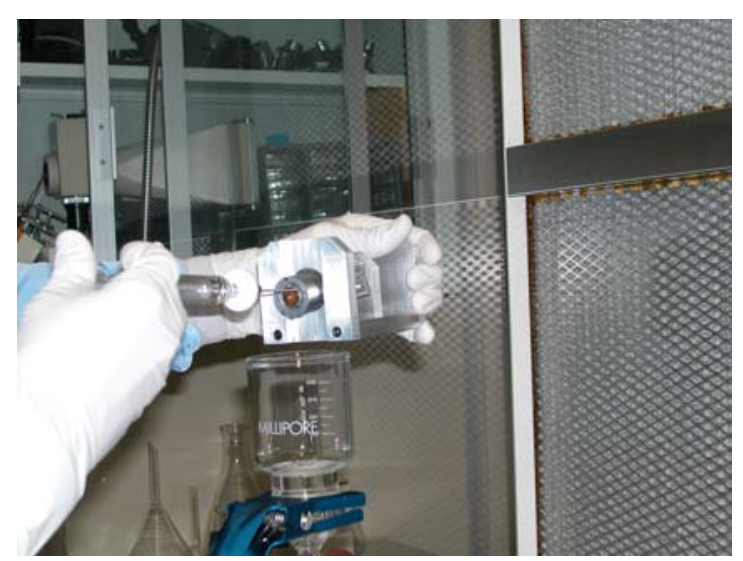

Figure 26. Capturing silicon oil

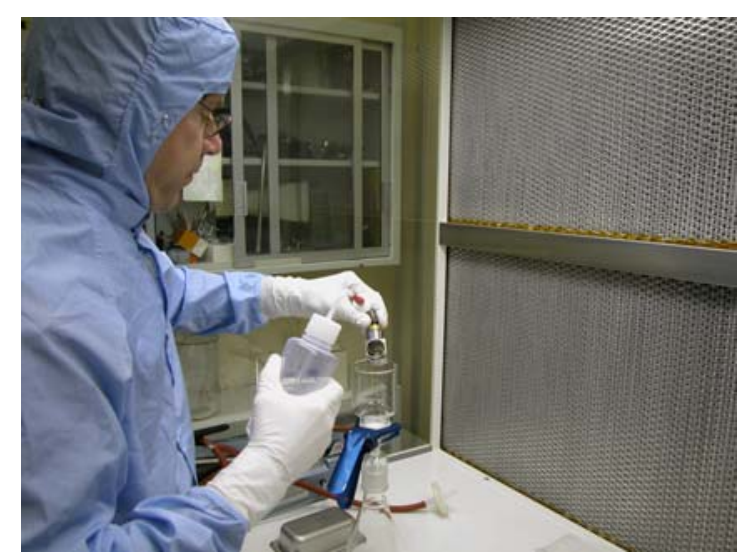

Figure 27. Filtering silicon oil

\section{Stronglink Activities}

706426 MC4654 ISL and 706635 MC4653 TSL

\section{MC4654 ISL}

Molydisulfide Lubrication on MC4710, MC4711, MC4653, and MC4654

(See previous section of this report.) This process was developed on the ISL and utilized on all four stronglinks.

\section{Rotor Assembly Process Improvement}

The MC4654 and MC4710 solenoid rotor assembly was a welded assembly that required a fixture for orientation. However, the rotor is Hiperco 50 which cracks during welding and does 
not yield a robust weld. KCP recommended that a bolted assembly with a mistake proofing pin for orientation between the rotor and the shaft be incorporated. The recommendation was accepted and incorporated into the development phases of MC4654 and MC4710.

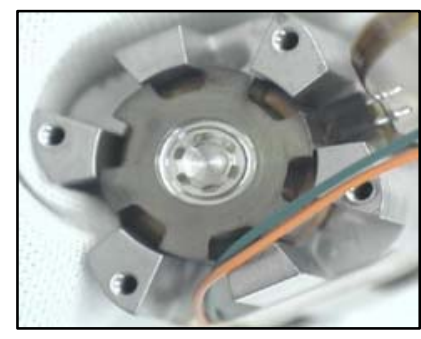

Figure 28. Hiperco welded rotor assembly

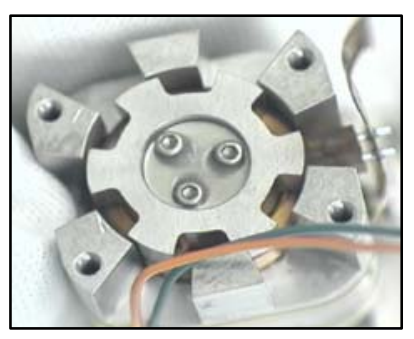

Figure 29. Bolted assembly with mistake proofing pin

\section{MC4653 TSL}

Development tester DT1200 was designed and built to fully automated a very tedious testing process on the MC4653. It was estimated that it reduced the testing time by $70 \%$ between Group 1 and Group 2 development builds. The magnetic shutter TSLs require more testing for magnetic shuttering and coupling than the non-magnetic devices. DT1200 most likely would have been utilized as an in-process tester for the MC4653 had it gone into production.

Redesign of Flex Cables and Attachment. During Development Group 2, 20\% of the units had a flex cable failure during environmental testing. The cause was an inadequate coil bonding process which was design dictated and a flex cable design that was not robust. KCP engineers designed and fabricated a new flex cable design and suggested a more robust bonding process.

Process Development. The team designed and fabricated potting, lapping, and grinding fixtures for the primary and secondary assemblies. The team also developed bonding processes at KCP and with vendors for the Safe/Enable Wheel.
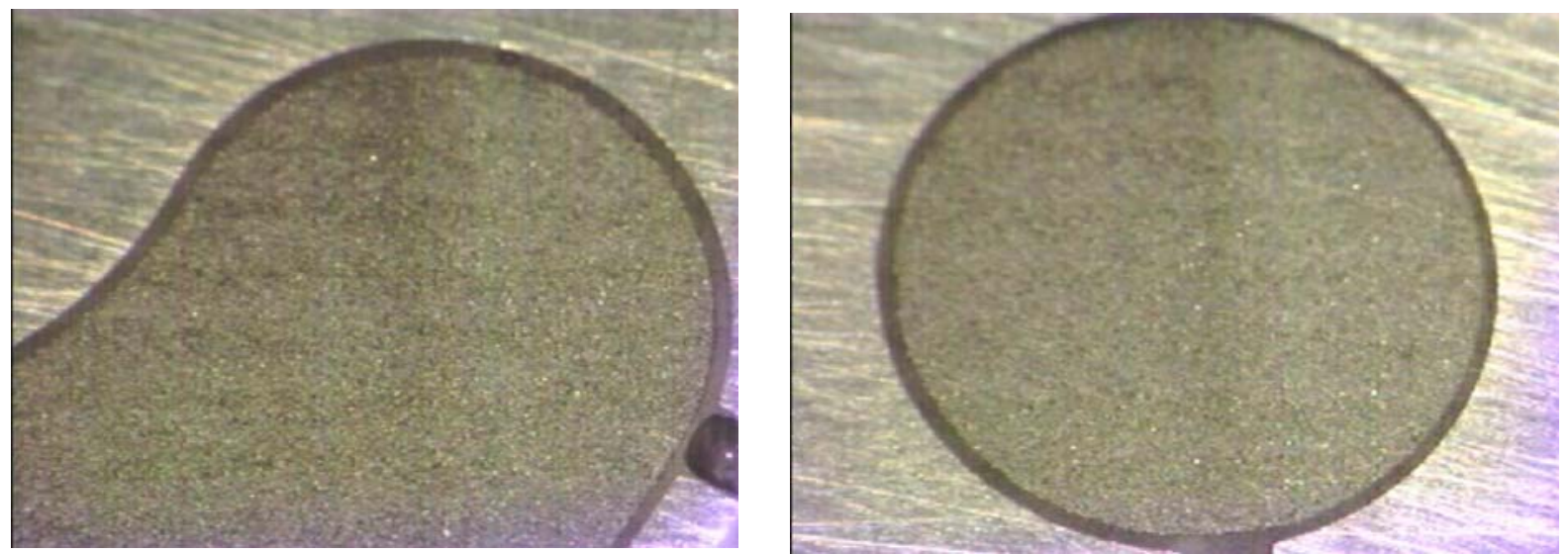

Figures 30 and 31. Photos of MC4653 TSL Safe/Enable wheel showing centering of the ferrites with respect to the stainless steel S/E wheel. 


\section{Header Solder Evaluation (Both TSLs)}

KCP performed solder evaluation on traditional glass-to-metal seal headers for the MC4653 TSL and the MC4711 TSL. The goal of this study was to investigate the impact on header assemblies by soldering the pins. This study was performed on the three different headers for the TSLs. The three types of tests conducted were: (1) repeated soldering cycles;

(2) thermocouple mapping of the pin, glass, and header body during soldering, and (3) thermal cycling in an environmental test chamber. No hermetic degradation was observed in the pins after multiple soldering cycles and thermal cycling tests. Headers studied met the drawing requirements for leak rate both before and after soldering. Soldering to the pins has not caused deterioration in the sealing properties of the glass.

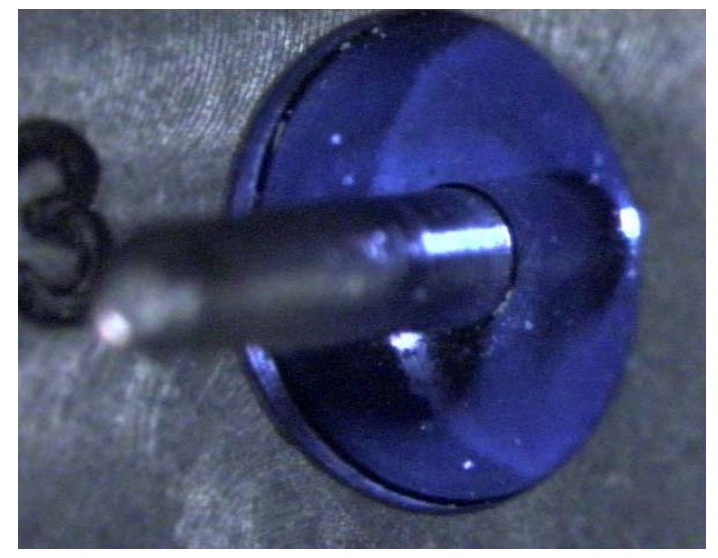

Figure 32. Test pin and sealing glass after solder and thermal cycling tests. 